\title{
Incidence and impact on prognosis of heart failure in Middle Eastern patients undergoing percutaneous coronary interventions
}

\author{
Ayman J Hammoudeh1, Dalal Al-Natour'2, Yousef Khader ${ }^{3}$, Imad A Alhaddad ${ }^{4}$, \\ Ramzi Tabbalat ${ }^{5}$, Eyas Al-Mousa ${ }^{1,6}$, Akram Saleh ${ }^{7}$ \\ ${ }^{1}$ Interventional Cardiologist, Department of Cardiology, Istishari Hospital, ${ }^{2}$ Medical Pharmacist, Department of \\ Pharmacy Services, Jordan Hospital, Queen Noor, Amman, ${ }^{3}$ Professor, Department of Community Medicine, School of \\ Allied Medical Sciences, Jordan University of Science and Technology, Irbid, ${ }^{4}$ Interventional Cardiologist, Department \\ of Cardiology, Jordan Hospital, ${ }^{5}$ Interventional Cardiologist, Department of Cardiology, Khalidi Medical Center, \\ ${ }^{6}$ Assistant Professor, Department of Internal Medicine, Cardiology Section, Jordan University Hospital, ${ }^{7}$ Professor, \\ Department of Internal Medicine, Cardiology Section, Jordan University Hospital, Amman, Jordan
}

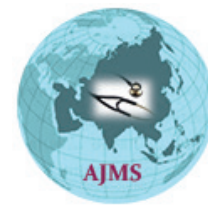

A B S T R A C T

Background: Heart failure (HF) is a serious complication of percutaneous coronary intervention ( $\mathrm{PCl}$ ) that adversely impacts survival and quality of life. Aims and Objectives: We sought to study the incidence of $\mathrm{HF}$ in Middle Eastern patients undergoing $\mathrm{PCl}$ and its impact on prognosis. Materials and Methods: The first Jordanian PCl Registry was a prospective multicenter study of $\mathrm{PCl}$ patients who were followed for one year. Patients who developed heart failure during hospitalization had their clinical and coronary angiographic profiles and adverse outcomes compared with those in patients who did not develop HF. Results: Of 2425 patients who had $\mathrm{PCl}, 194$ (8.0\%) developed HF during the hospital stay. Compared with patients who did not develop HF, those who developed HF were more likely to have diabetes mellitus, prior history of myocardial infarction (MI), elevated levels of cardiac biomarkers, ST-segment elevation $\mathrm{MI}$ and multivessel or left anterior descending coronary artery disease (all $p$ values $<0.05$ ). Cardiac mortality was significantly higher among patients who developed HF compared with those who did not $(5.2 \%$ vs. $0.4 \% ; p<0.0001)$ and at one year $(11.2 \%$ vs. $1.2 \% ; \mathrm{p}<0.001)$. Multivariate analysis showed that HF during hospital stay was an independent predictor of one-year cardiac mortality (Odds ratio $6.1,95 \% \mathrm{CI}$ 3.3-11.1, $\mathrm{p}<0.001)$. At one year, readmission rates for HF and ACS were higher among HF patients. Conclusions: Certain clinical and angiographic features were associated with higher incidence of HF among Middle Eastern patients who undergo PCl. HF was associated with higher risk of death and other adverse cardiac events during hospital stay and one year of follow up.

Key words: Heart failure, Percutaneous coronary intervention, Outcome, Prognosis
http://nepjol.info/index.php/AJMS DOI: 10.3126/ajms.v8i2.15872 E-ISSN: 2091-0576 P-ISSN: 2467-9100

\section{INTRODUCTION}

Heart failure (HF) is a serious complication of acute coronary syndrome (ACS) and percutaneous coronary intervention (PCI) and has a substantial impact on patient survival and quality of life. ${ }^{1-3} \mathrm{HF}$ due to left ventricular (LV) systolic dysfunction in patients admitted for ACS or those who undergo PCI is not only a determinant of high incidence rate of in-hospital complications and worse procedural outcome, but also of long-term outcome. ${ }^{4-6}$ HF has not been studied in patients following PCI for ACS or stable coronary disease in the Middle East where cardiovascular disease is the leading cause of death and heart failure, and where an increasing number of relatively young patients are admitted with ACS and undergo PCI. ${ }^{7-9}$

Studies that assessed the prevalence of heart failure in Middle Eastern ACS populations, did not address HF 
in an exclusive PCI population, and did not evaluate the impact of HF during hospital stay on the incidence of adverse cardiovascular events, including cardiac mortality and readmission for HF and ACS after hospital discharge to one year of follow up. ${ }^{10-13}$ The recently completed first Jordanian PCI Registry (JoPCR1) assessed the in-hospital and one-year outcomes in patients who underwent PCI for ACS and stable coronary disease. ${ }^{14-15}$ We used data from this registry to evaluate the incidence, clinical and coronary angiographic features, predictive factors, in-hospital and one-year prognosis in patients who developed HF during the hospital stay compared with those who did not.

\section{MATERIALS AND METHODS}

JoPCR1 is a prospective, observational, multicenter registry of consecutive patients who underwent PCI at 12 tertiary care centers in Jordan between January 2013 and February 2014. A case report form was used to record data prospectively at hospital admission and discharge. At one, 6 and 12 months after the index hospitalization, data were collected during out-patient clinic visits or by phone calls to patients, household relatives or primary care physicians. The study was approved by the Institutional Review Board of each participating hospital. Baseline data included clinical, laboratory, electrocardiographic (ECG), echocardiographic, and coronary angiographic features. LV ejection fraction (LVEF) was determined by 2-D transthoracic echocardiography in accordance with current guidelines, ${ }^{16}$ or by contrast left ventriculography during cardiac catheterization. Details of the PCI procedure and its outcome were prospectively recorded.

HF was diagnosed by the presence of pulmonary rales, chest radiography showing pulmonary venous congestion and LVEF $<40 \% .{ }^{17}$ The diagnosis of cardiogenic shock was based on the presence of pulmonary venous congestion in association with systolic blood pressure $<90 \mathrm{mmHg}$ and signs of peripheral vasoconstriction including diaphoresis, cyanosis and oliguria. ${ }^{18} \mathrm{All}$ PCI procedures were performed according to current standard guidelines. The arterial access site, type and number of stents and the use of intravenous glycoprotein inhibitors were left to the operator's discretion. All patients received dual oral antiplatelet therapy, which consisted of aspirin, and either clopidogrel (300-600 mg) or ticagrelor $(180 \mathrm{mg})$ loading dose, and a loading dose of unfractionated heparin (100 IU/kg body weight) to keep the activated clotting time $\approx 300$ seconds throughout or immediately at the conclusion of the PCI procedure. PCI was indicated for either ACS or stable coronary disease.

ACS was classified as acute ST-segment elevation myocardial infarction (STEMI), defined by the presence of cardiac ischemic chest pain, ST-segment elevation of $>2 \mathrm{~mm}$ in at least 2 contiguous leads on the 12-lead ECG, and elevated cardiac biomarkers; or non-ST-segment elevation ACS (NSTEACS), which included NSTEMI, defined by the presence of cardiac ischemic chest pain, ST-segment depression, inverted T wave, or normal ECG and elevated cardiac biomarkers, and unstable angina (UA), defined similar to NSTEMI with no elevation of cardiac biomarkers on admission or 8-12 hours later. Stable coronary disease was defined as either chronic stable angina (ischemic cardiac pain on effort that did not change in severity for the past 3 months, and absence of resting ECG ischemic changes or elevated cardiac biomarkers); or silent ischemia, defined by the absence of angina in the presence of signs of myocardial ischemia on ECG, echocardiography, or nuclear myocardial scan.

PCI for STEMI was primary (PCI as the initial reperfusion strategy with no fibrinolysis); rescue (after failure of fibrinolysis); or elective (after successful fibrinolysis). PCI for NSTEACS was urgent (done within 2 hours after admission for ongoing chest pain, hemodynamic instability, life-threatening ventricular arrhythmias or heart failure); early invasive (within 24 hours after admission); or invasive (within 24-72 hours after admission).

Clinical profiles, coronary angiographic features and complications of the PCI procedure were compared in patients who developed HF during hospital stay and those who did not. We also compared the incidence of adverse cardiovascular events including cardiac mortality, stent thrombosis (ST), major bleeding events, coronary revascularization and readmission for HF and ACS in the two groups up to one year of follow up. Cardiac mortality was defined as any death not attributed to a clear non-cardiac cause. ST, definite or probable, was defined according to the Academic Research Consortium definition. ${ }^{19}$ Major bleeding events were defined according to the CRUSADE study definition and included intracranial hemorrhage, retroperitoneal bleeding, hematocrit (Hct) drop $>12 \%$ from baseline, any red blood cell (RBC) transfusion when baseline Hct was $>28 \%$, or any RBC transfusion when baseline Hct was $<28 \%$ with witnessed bleeding. ${ }^{20}$

\section{Statistics}

IBM SPSS Statistics 20 (IBM Corp., 2011) was used for data entry and analysis. Data were described using means and percentages. Chi-square test was used to test differences between proportions, and independent $t$ test was used to test differences between the means in the two groups of patients who developed HF and those who did not. A binary logistic regression was used to test the difference in death rate during hospital stay between the two groups. 
Candidate variables for these models were selected based on clinical importance, previously developed models, and a review of related literature.

These variables were female gender, age $>60$ year of age, diabetes mellitus, hypertension, body mass index $>30 \mathrm{~kg} / \mathrm{m}^{2}$, past history of $\mathrm{MI}$, past history of $\mathrm{HF}$, STEMI, elevated levels of cardiac biomarkers, left anterior descending (LAD) coronary or multivessel coronary artery involvement. The significant variables that were kept in the regression model were age, diabetes mellitus, history of $\mathrm{HF}$, STEMI, and HF during hospital stay. A p-value of less than 0.05 was considered statistically significant.

\section{RESULTS}

Of the 2425 patients who underwent PCI, the procedure was indicated for ACS in $1870(77.1 \%)$ and for stable coronary disease in 555 (22.9\%). Past diagnosis of HF was reported by 15 patients $(0.62 \%)$ and HF during hospital stay was diagnosed in 194 patients (8.0\%). This diagnosis was made on admission in 44 patients $(22.7 \%)$, during the first hospital day in 77 (39.7\%), and between the second day and hospital discharge in $73(37.6 \%)$. The length of stay was $<3$ days in the majority $(\mathrm{N}=133,72.3 \%)$ of patients who developed HF. Among the different subgroups of ACS, those with STEMI developed HF during hospital stay more than those with NSTEMI or UA $(12.0 \%, 7.8 \%$, and $5.1 \%$; respectively; $\mathrm{p}<0.001)$.

Table 1 depicts the clinical and coronary angiographic features in patients diagnosed to have HF compared with those who did not HF. LVEF was $<40 \%$ in the majority $(93 \%)$ of the patients who developed HF. Of all studied clinical features, patients who developed HF were more likely to have diabetes mellitus and previous history of HF. There were no significant differences between the two groups in the prevalence rates of other major risk factors including gender, hypertension, overweight or smoking. Patients who developed HF were more likely to have ST-segment elevation on ECG and elevated blood levels of cardiac biomarkers compared with patients who did not develop HF.ACS was the indication for PCI in nearly similar proportions of patients who developed $\mathrm{HF}$ and those who did not $(79.4 \%$ and $76.8 \%$, respectively, $\mathrm{p}=0.49)$, but STEMI was diagnosed in a significantly higher proportion of the HF patients (Table 2). Patients with HF were more likely to have involvement of the LAD coronary artery or multivessel CAD compared with patients who did not have HF. Among the patients with STEMI, anterior wall involvement was more common among those who developed HF compared with those who did not (69/87; $79.3 \%$ vs. $412 / 639,64.5 \%, p=0.01)$.

There was no difference between the proportions of patients who had multivessel PCI in the two groups. Most of the stents used in this contemporary PCI registry were second generation drug-eluting stents (89.4\%). Bare metal stents and bioabsorbable scaffolds were used in $9.6 \%$ and $1.0 \%$; respectively. Types of stents were not different in patients with $\mathrm{HF}$ and those without $\mathrm{HF}$.

Patients with HF suffered higher rates of serious in-hospital complications and needed more invasive procedures

\begin{tabular}{|c|c|c|c|}
\hline Features & Patients with HF n (\%) (N=194) & Patients with no HF n (\%) (N=2231) & p-value \\
\hline Age in years, mean $\pm S D$ & $59.4 \pm 11.5$ & $58.3 \pm 10.8$ & 0.23 \\
\hline Women & $42(21.6)$ & $458(20.5)$ & 0.79 \\
\hline Hypertension & $123(63.4)$ & $1387(62.2)$ & 0.80 \\
\hline Hypercholesterolemia & $96(49.5)$ & $1088(48.8)$ & 0.91 \\
\hline Diabetes mellitus & $119(61.3)$ & $1180(53.0)$ & 0.03 \\
\hline Cigarette smoking & $80(41.2)$ & $975(43.7)$ & 0.55 \\
\hline Previous MI & $20(10.3)$ & $242(10.8)$ & 0.92 \\
\hline Previous $\mathrm{PCl}$ & $53(27.3)$ & $546(24.5)$ & 0.44 \\
\hline Previous CABG & $9(4.6)$ & $76(3.4)$ & 0.50 \\
\hline Past history of heart failure & $5(2.6)$ & $10(0.4)$ & $<0.001$ \\
\hline $\mathrm{BMI} \mathrm{kg} / \mathrm{m}^{2}$, mean $\pm \mathrm{SD}$ & $27.7 \pm 4.5$ & $28.0 \pm 4.5$ & 0.37 \\
\hline Chronic renal failure & $7(3.6)$ & $62(2.8)$ & 0.68 \\
\hline Estimated creatinine clearance $\leq 60 \mathrm{ml} /$ minute & $34(17.5)$ & $287(12.9)$ & 0.09 \\
\hline ST-segment elevation & $89(45.9)$ & $655(29.4)$ & $<0.001$ \\
\hline ST-segment depression & $42(21.6)$ & $395(17.7)$ & 0.21 \\
\hline Elevated serum cardiac biomarkers & $106(54.6)$ & $864(38.7)$ & $<0.001$ \\
\hline LVEF $<40 \%$ & $180(92.8)$ & $122(5.5)$ & $<0.001$ \\
\hline
\end{tabular}

BMI: Body mass index; BP: Blood pressure; CrCl: Creatinine clearance; HDL-C: High-density lipoprotein cholesterol; HF: Heart failure; LDL-C: Low-density lipoprotein cholesterol; LVEF: Left ventricular ejection fraction; PAD: Peripheral arterial disease; PCI: Percutaneous coronary intervention 
including endotracheal intubation, ventilatory support and intra-aortic balloon counterpulsation than patients who did not develop HF.

After discharge from the hospital, HF patients continued to have higher rates of adverse cardiovascular events (Table 3). Specifically, they had higher incidence of ST and higher rates of readmission for HF and coronary revascularization. Cardiac mortality occurred at a significantly higher rate among patients with $\mathrm{HF}$ compared with those who did not have HF, from the time of admission to one year of follow up. Nineteen patients (all had ACS) died during the index hospitalization; $10(5.2 \%)$ were among the HF group and $9(0.4 \%)$ among the patients who did not have HF. Among patients in the three subgroups of ACS; STEMI, NSTEMI and UA, death rates among HF patients were higher than those with no HF (Table 4). No deaths during hospital stay occurred in patients who had stable coronary disease. Table 5 shows the multivariate analysis of the association between HF during hospital stay and death at 1 year after adjusting for important predictors of mortality. Patients

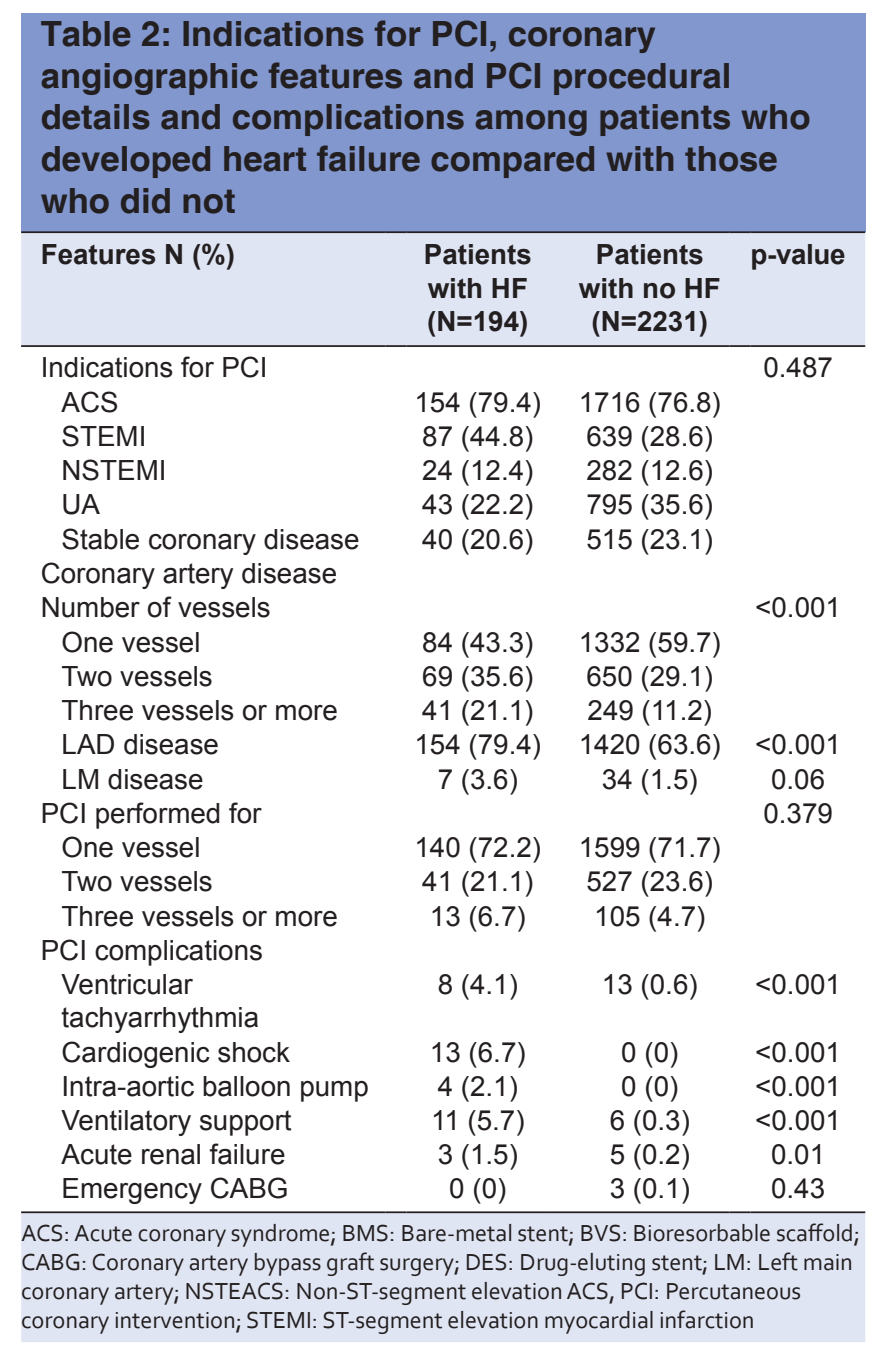

who had HF during hospital stay and those who had history of $\mathrm{HF}$ in the past had higher odds of mortality at 1 year compared to those who had no HF during hospital stay $(\mathrm{p}<0.001)$.

Of 194 patients with HF, 13 developed cardiogenic shock (8 had STEMI, 4 UA and 1 NSTEMI). Eleven patients had LAD and one patient had left main coronary artery involvement. Seven patients with cardiogenic shock died during hospitalization (54\%) and at one month death rate was $62 \%$.

Thrombolytic medications were used during hospital stay in a minority of patients who developed or did not develop HF (2.6\% and 3.4\%; respectively, $\mathrm{p}=0.70)$. During hospital stay, all HF patients received dual oral antiplatelet agents (DAPT), 80.9\% received beta blockers (BB), 63.4\% received renin angiotensin aldosterone blockers (RAASB) and 93.4\% received statins. At one year, these medications were used by $90.9 \%, 83.5 \%$, $69.3 \%$, and $93.4 \%$, respectively, among HF patients. These rates were not different from those of those who did not develop HF.

\begin{tabular}{|c|c|c|c|}
\hline $\begin{array}{l}\text { Events and timing } \\
\mathbf{N}(\%)\end{array}$ & $\begin{array}{l}\text { Patients } \\
\text { with HF } \\
(\mathrm{N}=194)\end{array}$ & $\begin{array}{c}\text { Patients } \\
\text { without } \\
\text { HF } \\
(\mathrm{N}=2231)\end{array}$ & p-value \\
\hline In-hospital & & & $<0.001$ \\
\hline Stent thrombosis & $4(2.1)$ & $5(0.2)$ & 0.80 \\
\hline Major bleeding events & $2(1.0)$ & $21(0.9)$ & $<0.001$ \\
\hline \multirow[t]{2}{*}{ Cardiac mortality } & $10(5.2)$ & $9(0.4)$ & \\
\hline & $\mathrm{N}=184$ & $\mathrm{~N}=2202$ & \\
\hline One month & & & $<0.001$ \\
\hline Stent thrombosis & $10(5.3)$ & $23(1.04)$ & 0.81 \\
\hline Major bleeding events & $3(1.6)$ & $24(1.1)$ & $<0.001$ \\
\hline Cardiac mortality & $14(7.3)$ & $15(0.7)$ & $<0.001$ \\
\hline $\begin{array}{l}\text { Coronary } \\
\text { revascularization }\end{array}$ & $8(4.4)$ & $22(1.0)$ & \\
\hline \multicolumn{4}{|l|}{ Readmission for } \\
\hline $\begin{array}{l}\text { Acute coronary } \\
\text { syndrome }\end{array}$ & $8(4.4)$ & $33(1.5)$ & 0.01 \\
\hline \multirow[t]{2}{*}{ Heart failure } & $6(3.3)$ & $7(0.3)$ & $<0.001$ \\
\hline & $\mathrm{N}=176$ & $\mathrm{~N}=2171$ & \\
\hline One year & & & $<0.001$ \\
\hline Stent thrombosis & $13(7.0)$ & $34(1.6)$ & 0.96 \\
\hline Major bleeding events & $3(1.6)$ & $27(1.2)$ & $<0.001$ \\
\hline Cardiac mortality & $21(11.2)$ & $26(1.2)$ & 0.002 \\
\hline $\begin{array}{l}\text { Coronary } \\
\text { revascularization }\end{array}$ & $13(7.0)$ & $60(2.7)$ & \\
\hline \multicolumn{4}{|l|}{ Readmission for } \\
\hline $\begin{array}{l}\text { Acute coronary } \\
\text { syndrome }\end{array}$ & $14(7.7)$ & $108(5.0)$ & 0.17 \\
\hline Heart failure & $13(7.0)$ & $16(0.7)$ & $<0.001$ \\
\hline
\end{tabular}




\begin{tabular}{|c|c|c|c|}
\hline $\begin{array}{l}\text { Group of } \\
\text { patients }\end{array}$ & $\begin{array}{l}\text { HF patients } \\
\text { who died } \\
\text { during } \\
\text { hospitalization, } \\
\text { N (\%) }\end{array}$ & $\begin{array}{c}\text { Non-HF } \\
\text { patients who } \\
\text { died during } \\
\text { hospitalization, } \\
\mathrm{N}(\%)\end{array}$ & $p$-value \\
\hline All patients & $10 / 194(5.2)$ & $9 / 2231(0.4)$ & $<0.001$ \\
\hline STEMI & $6 / 87(6.9)$ & $6 / 639(0.9)$ & 0.002 \\
\hline NSTEMI & $2 / 24(8.3)$ & $1 / 282(0.4)$ & 0.008 \\
\hline $\begin{array}{l}\text { Unstable } \\
\text { angina }\end{array}$ & $2 / 43(4.7)$ & $2 / 795(0.3)$ & 0.005 \\
\hline $\begin{array}{l}\text { Stable } \\
\text { coronary } \\
\text { disease }\end{array}$ & $0 / 40(0)$ & $0 / 515(0)$ & - \\
\hline
\end{tabular}

HF: Heart failure; NSTEMI: Non-ST-segment elevation myocardial infarction; STEMI: ST-segment elevation myocardial infarction.

\begin{tabular}{|c|c|c|c|}
\hline Variable & $\begin{array}{l}\text { Odds } \\
\text { ratio }\end{array}$ & $\begin{array}{c}95 \% \\
\text { confidence } \\
\text { interval }\end{array}$ & p-value \\
\hline $\begin{array}{l}\text { Prior history of heart } \\
\text { failure }\end{array}$ & 8.6 & $(4.7,15.8)$ & $<0.001$ \\
\hline Heart failure on admission & 6.1 & $(3.3,11.1)$ & $<0.001$ \\
\hline Age (>60 vs. $\leq 60)$ & 2.3 & $(1.2,4.1)$ & 0.008 \\
\hline $\begin{array}{l}\text { ACS type } \\
\text { (STEMI vs. NSTEACS) }\end{array}$ & 2.2 & $(1.2,3.9)$ & 0.013 \\
\hline Diabetes mellitus & 1. 9 & $(1.2,3.6)$ & 0.052 \\
\hline
\end{tabular}

ACS: Acute coronary syndrome; NSTEACS: Non ST-segment elevation acute coronary syndrome; STEMI: ST-segment elevation myocardial infarction.

\section{DISCUSSION}

The main findings of this study of Middle Eastern patients undergoing PCI are (1) 8.0\% developed HF during hospital stay, (2) patients who developed HF were more likely to have diabetes or prior MI, present with STEMI and have involvement of the LAD or multivessel CAD than those who did not develop HF, and (3) we have shown for the first time in a Middle Eastern study that HF was associated with high incidence rates of in-hospital complications and was an independent predictor of one-year adverse cardiovascular events.

HF complicates ACS as a result of a complex interaction of structural, hemodynamic, and neurohormonal maladaptations related to the abrupt myocyte loss associated with MI leading to contractile dysfunction. ${ }^{21,22}$ Patients who do not have extensive myocyte necrosis due to acute MI, post ischemic LV systolic dysfunction leading to HF can result from transient myocardial stunning or hibernation depending on the extent of coronary reperfusion. ${ }^{23,24}$ Ischemia or MI leading to systolic or diastolic dysfunction may precipitate pulmonary edema, output failure or cardiogenic shock. ${ }^{21,22,24}$ In addition to systolic dysfunction as a major cause of HF in patients with ACS, recent metaanalysis showed that restrictive mitral filling pattern, the most severe form of diastolic dysfunction, was present in approximately $10 \%$ of patients with preserved EF who developed $\mathrm{HF}^{25}$ However, the true prevalence and relevance of diastolic dysfunction after MI remains to be elucidated. ${ }^{26} \mathrm{LV}$ systolic dysfunction in patients with stable coronary disease is attributed to myocardial ischemia or hibernation, or prior infarction. ${ }^{27,28}$

HF during hospital stay should be distinguished from pre-existing HF reported by patients on admission, which was present in $2.6 \%$ of patients who developed HF in this study. Pre-existing HF is related to different pathophysiological mechanisms mainly related to older age and higher incidence of comorbidities and risk factors. Such patients can develop HF during hospital stay due to a new episode of ischemia or infarction, or a clear precipitant or trigger, including an arrhythmia, discontinuation of diuretic therapy, volume overload, infection or severe hypertension..$^{27,29}$

The incidence rate of HF in this registry was less than that reported by other studies and registries that enrolled patients ACS and PCI in this region and other regions. The Global Registry of Acute Coronary Events (GRACE) that enrolled STEMI and NSTEACS patients reported an overall $\mathrm{HF}$ incidence of $13 \%$, and a meta-analysis of seven clinical trials that enrolled $>46,000$ patients with NSTEACS reported a HF rate of $13.5 \%$ from hospital admission to discharge ${ }^{6}$ Two studies from the Middle East reported HF rates of $13 \%$ and $25 \%$; respectively. ${ }^{10,13}$ Rate of HF incidence among patients with STEMI in our study (12\%) was also lower than rates reported by others. HF rate of $16 \%$ was reported by the GRACE investigators, ${ }^{30} 17 \%$ and $24 \%$ by a Canadian study in primary PCI and no PCI patients; respectively, ${ }^{31} 18 \%$ by the Which Early ST-elevation Myocardial Infarction Therapy (WEST) trial, ${ }^{32} 23 \%$ by the Valsartan in Acute Myocardial Infarction trial (VALIANT), ${ }^{33} 29 \%$ in meta-analysis of four major thrombolysis trials, ${ }^{34}$ and $29 \%$ by others. ${ }^{35}$

The variation in the incidence rates of HF in the setting of ACS among registries and studies is mainly due to different populations enrolled, case ascertainment and diagnostic criteria used in each study and the use of invasive diagnostic and revascularization procedures. . $3,30,34^{2}$ This registry enrolled only patients who underwent PCI, thus had an advantage of a procedure proven to preserve myocardium and decrease the incidence of HF. ${ }^{36-38}$ Studies from our region vary in the frequency 
of utilization of invasive strategy for patients admitted with ACS. High rates of coronary angiography $(70 \%)$, PCI $(60 \%)$ and primary PCI $(90 \%)$ rates were reported by some investigators, ${ }^{9,39,40}$ and others reported rates as low as $8 \%$ to $19 \% .^{11,12}$

As we and others have indicated, patients with HF had higher prevalence of multiple comorbidities and cardiac risk factors including diabetes mellitus, prior MI, STEMI, elevated blood levels of cardiac biomarkers and multivessel CAD. ${ }^{6}$ Other high-risk baseline characteristics found to be associated with developing HF include prior HF, older age, female gender, race, current smoker status, hypertension, hyperlipidemia, prior angina or stroke, peripheral vascular disease, previous coronary artery bypass graft surgery (CABG), admission diagnosis of STEMI or NSTEMI, ST-segment changes, anterior STsegment elevation, post-revascularization $\mathrm{Q}$ waves on ECG, right bundle branch block, LVEF $<30 \%$, Killip class $>2$ at presentation, higher presenting heart rate, atrial fibrillation, ventricular tachycardia, and baseline TIMI grade 0 flow. ${ }^{6,31,32,36,41-45}$ Close attention to patients with those baseline characteristics in the setting of ACS and PCI, vigilance for early signs of $\mathrm{HF}$ and implementing preventive treatment, such as earlier use of the RAASB and $\mathrm{BB}$ might potentially lower the rate of $\mathrm{HF}$ during hospital stay in such patients. ${ }^{6}$

Rare, but serious, causes of HF in patients who have STEMI include ventricular septal defect, acute mitral valve insufficiency due to ischemia or infarction and rupture of a papillary muscle or chordae. These complications, however, are rare, but lead to cardiogenic shock in the majority of patients and is associated with high early mortality. ${ }^{45}$

Cardiogenic shock developed in 13 patients in this study (6.7\% or HF patients; $0.04 \%$ of all patients), a rate much lower than that reported by others and ranges between $3 \%$ and $5.4 \% .{ }^{46-48}$ While most of $\mathrm{HF}$ cases complicating NSTEACS are manifested by pulmonary edema, over half of patients with cardiogenic shock have concomitant STEMI. This underlines the importance of early invasive strategy in these patients because mortality rate among patients who developed cardiogenic shock is prohibitively high and exceeds $50 \% .^{24}$ Recent guidelines advocate an immediate aggressive invasive and coronary revascularization approach by $\mathrm{PCI}$ or $\mathrm{CABG}$ depending on coronary anatomy. ${ }^{46,48}$ Intra-aortic balloon counterpulsation was used in a small percentage (2.1\%) of HF patients in this study. The value of this intervention has been challenged when used in patients suffering cardiogenic shock. ${ }^{46}$

HF due to impaired LV systolic function at the time of admission for ACS or during primary PCI for STEMI has been shown to be an independent predictor of reduced early (during hospital stay and at 30 days) and late survival and future MI., ${ }^{4,45,48} \mathrm{HF}$ developing at any time during hospitalization for patients with STEMI, NSTEMI or UA is independently associated with poor outcomes. We demonstrated in this study that death rates among patients with any of the sub-types of ACS were significantly higher among those who developed HF compared with those who did not. We demonstrated that HF was an independent predictor of one year mortality in the studies population.

Mortality rates among HF patients in this study during hospital stay $(5.1 \%)$ and at one year $(11.2 \%)$ were lower than those reported by other investigators from this region and other regions. In one study, in-hospital death rate ranged between $12 \%$ and $18 \%$, depending on the sub-type of ACS. ${ }^{49,50}$ Another registry from this region reported a death rate of $7.9 \%$ during hospital stay. ${ }^{12} \mathrm{HF}$ on admission was associated with a marked increase in mortality rates at 30 days, 2 and 7.6 years. ${ }^{6,46,50}$ In addition to excess mortality, we also demonstrated, similar to others, increased rates of ST and coronary revascularization among patients with $\mathrm{HF}^{46}$

Recent studies have reported significant decreases in the rates of in-hospital death, cardiogenic shock, recurrent myocardial infarction, and heart failure in in the setting of ACS. ${ }^{51,52}$ Rates of HF fell by $9 \%$ in patients with STEMI and by $6.9 \%$ in those with NSTEMI. ${ }^{52}$ Potential explanations of this trend include the increasing use of evidence-based pharmacotherapies, adopting primary PCI as the treatment of choice for STEMI, higher rate of use of PCI for NSTEACS, and advances in PCI instrumentations. ${ }^{1,3,48,51}$

Evidence-based therapies and secondary cardiovascular prevention medications are indicated for patients with STEMI, NSTEACS, HF complicating ACS, and stable coronary disease patients with low LVEF or HF. ${ }^{32,33,45}$ These medications, that include DAPT, RAASB, BB, and statins, were prescribed in this study during hospital stay and at one year of follow up at similar rates in patients who developed or did not develop HF.

The study has few limitations similar to those of observational studies, including possible selection bias and not enrolling consecutive patients. Furthermore, the study did not include patients who died before arrival to hospital or before undergoing PCI or those who underwent diagnostic coronary angiography and were referred to CABG. The accuracy, concordance, and inter/ intra-observer variability in detecting $\mathrm{HF}$ among the patients could not be determined for obvious temporal and practical reasons. Data collection during hospitalization was 
complete for the whole cohort, and $1.5 \%$ of patients were lost to follow up at one year; a small percentage that would not significantly affect the one year outcome. Patients were enrolled by tertiary care centers, thus the results may not be generalizable to the broader population of patients with ACS treated in all hospitals in the region.

\section{CONCLUSIONS}

This study highlights several facts about HF complicating PCI in this Middle Eastern population. HF has an incidence rate less than that reported by similar studies and registries from this region and other regions. HF was associated with significant increased risk of in-hospital and one-year mortality. These results have important implications. Prompt revascularization and optimization of evidence-based therapies following PCI for ACS and stable coronary disease should be emphasized. There are baseline clinical and coronary angiographic characteristics that may identify patients at increased risk of developing heart failure among those admitted with ACS who undergo PCI. Vigilance for HF signs in such a group of patients and early treatment with evidence-based therapies could improve the in-hospital outcome and decrease the risk of future adverse events.

\section{Funding}

The study was supported by an unrestricted grant from AstraZeneca.

\section{REFERENCES}

1. Desta L, Jernberg T, Lofman I, Hofman-Bang C, Hagerman I, Spaak J, et al. Incidence, temporal trends, and prognostic impact of heart failure complicating acute myocardial infarction. The SWEDEHEART Registry (Sweden WebSystem for Enhancement and Development of EvidenceBased Care in Heart Diseases Evaluated According to Recommended Therapies): A study of 199,851 patients with index acute myocardial infarctions, 1996-2008. JACC Heart Fail 2015;3:234-242.

2. Consuegra-Sanchez $L$, Jaulent-Huertas $L$, Vicente-Gilabert $M$, Escudero-Garcia G, Diaz-Pastor A, Galcera-Tomas J, et al. Heart failure complicating acute myocardial infarction. Does the time of presentation matter? Int J Cardiol 2016;204:48-50.

3. Greco C, Rosato S, D'Errigo P, Mureddu GF, Lacorte E, Seccareccia $F$. Trends in mortality and heart failure after acute myocardial infarction in Italy from 2001-2011. Int J Cardiol 2015;184:115-121.

4. Amsterdam EA, Wenger NK, Brindis RG, Casey DE, Ganiats TG, Holmes DR Jr., et al. 2014 AHA/ACC guideline for the management of patients with non-ST-elevation acute coronary syndromes: A report of the American College of Cardiology/ American Heart Association Task Force on practice guidelines. Circulation 2014; 130:e344-e426.

5. Lala A, Desai AS. The role of coronary artery disease in heart failure. Heart Fail Clin 2014;10:353-365.
6. Bahit MC, Lopes RD, Clare RM, Newby K, Pieper KS, Van de Werf $F$, et al. Heart failure complicating non-ST-segment elevation acute coronary syndrome: Timing, predictors, and clinical outcomes. JACC Heart Fail 2013;1:223-229.

7. Alsheikh-Ali AA, Omar MI, Raal FJ, Rashed W, Hamoui O, KaneA, et al. Cardiovascular Risk factor burden in Africa and the Middle East: The Africa Middle East Cardiovascular Epidemiological (ACE) Study. PLoS ONE2014 Aug 4;9(8):e102830. Doi: 10.1371/journal.pone.0102830. eCollection 2014.

8. Yusuf S, Hawken S, Ounpuu S, Dans T, Avezum A, Lanas F, et al; INTERHEART Study Investigators. Effect of potentially modifiable risk factors associated with myocardial infarction in 52 countries (the INTERHEART study): Case-control study. Lancet 2004;364:937-952.

9. Hammoudeh AJ, Izraiq M, Hamdan $\mathrm{H}$, Tarawneh $\mathrm{H}$, Harassis $\mathrm{A}$, Tabbalat R, et al. High-sensitivity C-reactive protein is an independent predictor of future cardiovascular events in Middle Eastern patients with acute coronary syndrome. CRP and prognosis in acute coronary syndrome. Inter $\mathrm{J}$ Atheroscl 2008;3:50-55.

10. Al Suwaidi J, Al Habib K, Asaad N, Singh R, Hersi A, Al Falaeh H, et al. Immediate and one-year outcome of patients presenting with acute coronary syndrome complicated by stroke: Findings from the $2^{\text {nd }}$ Gulf Registry of Acute Coronary Events (Gulf RACE-2). BMC Cardiovascular Disorders 201212:64. doi: 10.1186/1471-2261-12-64.

11. Zubaid M, Rashed WA, Al-Khaja N, Almahmeed W, Al-Lawati J, Sulaiman K, et al. Clinical presentation and outcomes of acute coronary syndromes in the Gulf Registry of Acute Coronary Events (Gulf RACE). Saudi Med J 2008;29:251-255.

12. Alsheikh-Ali AA, Al-Mallah MH, Al-Mahmeed W, Albustani N, Al Suwaidi J, Sulaiman K, et al; for the Gulf RACE Investigators. Heart failure in patients hospitalized with acute coronary syndromes: Observations from the Gulf Registry of Acute Coronary Events (Gulf RACE). Eur J Heart Fail 2009,11:1135-1142.

13. Panduranga $\mathrm{P}, \mathrm{Al}$-Zakwani I, Sulaiman $\mathrm{K}$, Al-Habib $\mathrm{K}$, Alsheikh-Ali A, Al-Suwaidi J, et al. Comparison of Indian subcontinent and Middle East acute heart failure patients: Results from the Gulf Acute Heart Failure Registry. Indian Heart J 2015; doi:10.1016/j.inj.2015.11.019

14. Saleh A, Hammoudeh A, Tabbalat R, Al-Haddad I, Al-Mousa E, Jarrah $\mathrm{M}$, et al. Incidence and prognosis of stent thrombosis following percutaneous coronary intervention in Middle Eastern patients: The First Jordanian Percutaneous Coronary Intervention Registry (JoPCR1).Ann Saudi Med 2016;36:17-22.

15. Hammoudeh A, Alhaddad IA, Khader Y, Tabbalat R, Al-Mousa E, Saleh A, et al. Cardiovascular risk factors in Middle Eastern patients undergoing percutaneous coronary intervention: Results from the first Jordanian Percutaneous Coronary Intervention Study (JoPCR1), Journal of theSaudi Heart Association (2016), doi: http://dx.doi.org/10.1016/j.jsha.2016.10.002

16. Schiller NB, Shah PM, Crawford M, DeMaria A, Devereux R, Feigenbaum $\mathrm{H}$, et al. Recommendations for quantitation of the left ventricle by two-dimensional echocardiography. American Society of Echocardiography Committee on Standards, Subcommittee on Quantitation of Two-Dimensional Echocardiograms. J Am SocEchocardiogr 1989;2: 358-367.

17. Iraqi W, Rossignol P, Angioi M, Fay R, Nurr J, Ketelslegers JM, et al. Extracellularcardiac matrix biomarkers in patients with acute myocardial infarction complicated by left ventricular dysfunction and heart failure: Insights from the Eplerenone PostAcute Myocardial Infarction Heart Failure Efficacy and Survival Study (EPHESUS) Study. Circulation 2009;119:18 2471-2479.

18. Khot UN, Jia G, Moliterno DJ, Lincoff AM, Khot MB, Harrington RA, et al. Prognostic importance of physical 
examination for heart failure in non-ST-elevation acute coronary syndromes: The enduring value of Killip classification. JAMA 2003;290:2174-2181.

19. Cutlip DE, Windecker S, Mehran R, Boam A, Cohen DJ, van Es GE, et al, on behalf of the Academic Research Consortium. Clinical end points in coronary stent trials. A case for standardized definitions. Circulation 2007;115:2344-2351.

20. Subherwal S, Bach RG, Chen AY, Gage BF, Rao SV, Newby LK, et al. Baseline risk of major bleeding in non-ST-segment elevation myocardial infarction: The CRUSADE (Can Rapid risk stratification of Unstable angina patients Suppress ADverse outcomes with Early implementation of the ACC/AHA guidelines) Bleeding Score. Circulation 2009;119:1873-1882.

21. Velazquez EJ, Pfeffer MA. Acute heart failure complicating acute coronary syndromes. A deadly intersection. Circulation 2004;109:440-442.

22. Husebye T, Eritsland J, Arnesen H,Bjornheim R, Mangschau A, Seljeflot I, et al. Association of interleukin 8 and myocardial recovery in patients with ST-elevation myocardial infarction complicated by acute heart failure. PLoS ONE 2014. 9(11), e112359. http://doi.org/10.1371/journal.pone.0112359.

23. Zannad F, Stough WG, Pitt B. Heart failure as an endpoint in heart failure and non-heart failure cardiovascular clinical trials: The need for a consensus definition. Eur Heart $\mathrm{J}$ 2008;29:413-421.

24. Nieminen MS, Brutsaert D, Dickstein K, Drexler H, Follath F, Harjola VP, et al. EuroHeart Failure Survey II (EHFS II): A survey on hospitalized acute heart failure patients: Description of population. Eur Heart J 2006;27:2725-2736.

25. Meta-Analysis Research Group in Echocardiography (MeRGE) AMI Collaborators, Moller JE, Whalley GA, Dini FL, Doughty RN, Gamble GD, Klein AL, et al. Independent prognostic importance of a restrictive left ventricular filling pattern after myocardial infarction: An individual patient meta-analysis: Meta-Analysis Research Group in Echocardiography acute myocardial infarction. Circulation. 2008;117:2591-2598.

26. Minicucci MF, Azevedo PS, Polegato BF, PaivaSa, Zornoff LA. Heart failure after myocardial infarction: Clinical implications and treatment.Clin Cardiol 2011;34:410-414.

27. Gheorghiade M, De Luca L, Fonarow GC, Filippatos G, Metra M, Francis GS. Pathophysiologic targets in the early phase of acute heart failure syndromes. Am J Cardiol 2005;96:11-17.

28. Gheorghiade M, Bonow RO. Chronic heart failure in the United States: A manifestation of coronary artery disease. Circulation 1998;97:282-289.

29. Ponikowski P, Voors AA, Anker SD, Bueno H, Cleland JG, Coats AJ, et al.; on behalf of authors/task force members. 2016 ESC Guidelines for the diagnosis and treatment of acute and chronic heart failure. Eur Heart J 2016 published online 20 May 2016. http://dx.doi.org/10.1093/eurheartj/ehw128

30. Jhund PS, McMurray JJ. Heart failure after acute myocardial infarction. A lost battle in the war on heart failure? Circulation.2008;118:2019-2021.

31. DeGeare VS, Boura JA, Grines LL, O'Neill WW, Grines CL. Predictive value of the Killip classification in patients undergoing primary percutaneous coronary intervention for acute myocardial infarction. Am J Cardiol 2001;87:1035-1038.

32. Henriques JP, Zijlstra F, de Boer MJ. The prognostic importance of heart failure and age in patients treated with primary angioplasty. Eur J Heart Fail 2003;5:291-294.

33. McManus DD, Gore J, Yarzebski J, Spencer F, Lessard D, Goldberg RJ. Recent trends in the incidence, treatment, and outcomes of patients with STEMI and NSTEMI. Am Med 2011;124:40-47.

34. Spencer FA, Meyer TE, Gore JM, Goldberg RJ. Heterogeneity in the management and outcomes of patients with acute myocardial infarction complicated by heart failure: The National Registry of Myocardial Infarction. Circulation 2002;105:26052610.

35. Wu AH, Parsons L, Every NR, Bates ER; Second National Registry of Myocardial infarction. Hospital outcomes in patients presenting with congestive heart failure complicating acute myocardial infarction: A report from the Second National Registry of Myocardial Infarction (NRMI-2). J Am Coll Cardiol 2002;40:1389-1394.

36. Steg PG, Dabbous OH, Feldman LJ. Determinants and prognostic impact of heart failure complicating acute coronary syndromes: Observations from the Global Registry of Acute Coronary Events (GRACE). Circulation 2004;109:494-499.

37. Giugliano RP, White JA, Bode C. Early versus delayed, provisional eptifibatide in acute coronary syndromes. N Engl J Med 2009;360:2176-2190.

38. Werns SW, Bates ER. The enduring value of Killip classification. Am Heart J 1999;137:213-215.

39. Saleh A, Hammoudeh AJ, Hamam I, Khader YS, Alhaddad I, Nammas A, et al. Prevalence and impact on prognosis of glucometabolic states in acute coronary syndrome in a Middle Eastern country: The GLucometabolic abnOrmalities in patients with acute coronaRY syndrome in Jordan (GLORY) study. Inter J Diab Develop Countries 2012; 32:37-43.

40. Hammoudeh A, Saleh A, Hamam I, Alhaddad I, Bakri M, Nammas A, et al.The prognostic implications of TIMI risk scores in Jordanian patients with acute coronary syndrome. Results from the Glucometabolic Abnormalities in Acute Coronary Syndrome in Jordan (GLORY) Study. J Med J 2012;46:237-245.

41. Neskovic AN, Otasevic P, Bojic M, Popovic AD. Association of Killip class on admission and left ventricular dilatation after myocardial infarction: A closer look into an old clinical classification. Am Heart J 1999;137:361-367.

42. Granger CB, Goldberg RJ, Dabbous O, Pieper KS, Eagle KA, Cannon CP, et al. Global Registry of Acute Coronary Events Investigators predictors of hospital mortality in the Global Registry of Acute Coronary Events. Arch Intern Med 2003;163:2345-2353.

43. Fox KA, Dabbous OH, Goldberg RJ, Pieper KS, Eagle KA, Van de Werf F, et al. Prediction of risk of death and myocardial infarction in the six months after presentation with acute coronary syndromes: Prospective multinational observational study (GRACE). BMJ 2006;333:1091-1094.

44. Mehta SR, Eikelboom JW, Demers C, Maggiono AP, Commerford PJ, Yusuf S. Congestive heart failure complicating non-ST segment elevation acute coronary syndrome: Incidence, predictors, and clinical outcomes. Can J PhysiolPharmacol 2005;83:98-103.

45. Steg PG, Goldberg RJ, Gore JM. Baseline characteristics, management practices, and in-hospital outcomes of patients hospitalized with acute coronary syndromes in the Global Registry of Acute Coronary Events (GRACE). Am J Cardiol 2002;90:358-363.

46. Khalid L, and S.H Dhakam. A Review of Cardiogenic Shock in Acute Myocardial Infarction. Current Cardiology Reviews 2008:34-40.

47. lakobishvili Z, Behar S, Boyko V, Battler A and Hasdai S. Does current treatment of cardiogenic shock complicating the acute coronary syndromes comply with guidelines? Am Heart J 2005;149:98-103.

48. Wu C, Camacho FT, King SB $3^{\text {rd }}$, et al. Risk stratification for long-term mortality after percutaneous coronary intervention. Circ Cardiovasc Interv 2014;7:80-87.

49. Steg PG, Kerner A, Van de Werf F. Impact of in-hospital 
revascularization on survival in patients with non-STelevation acute coronary syndrome and congestive heart failure. Circulation 2008;118:1163-1171.

50. Gerber $Y$, Weston SA, Enriquez-Sarano M, Berardi C, Chamberlain AM, Jiang $R$, et al.Mortality associated with heart failure after myocardial infarction. Circ Heart Fail 2015;9:e002460.

51. McManus DD, Chinali M, Saczynski JS. 30-year trends in heart failure in patients hospitalized with acute myocardial infarction. Am J Cardiol 2011;107:353-359.+

\section{Authors Contribution:}

AJH - Study conceptualization and conduction, patient enrolling, literature review, manuscript draft and editing, and final manuscript writing; DAN - Study conception, patient enrolling, literature review, final manuscript writing and approval; YK - Study conception, statistical methodology, data analysis and interpretation, manuscript editing and approval;IAA- study conception and conduction, patient enrolling, manuscript draft and editing, and critical manuscript review; RT - Study conception and conduction, patient enrolling, manuscript draft and editing, and data interpretation; EAM - Literature review, data collection, drafting the initial manuscript, and critical manuscript revision; AS - Patients enrollment, data interpretation, manuscript drafting, and final manuscript writing

Source of Support: Nil, Conflict of Interest: None of the authors has potential conflict of interest related to this manuscript. 